Bol. Acad. peru. leng. 64. 2018 (235-246)

\title{
LA ELECCIÓN PARADIGMÁTICA DEL HOMÓNIMO PARASITARIO: ENTRE LA ECONOMÍA LINGÜÍSTICA Y LOS PRINCIPIOS PRAGMÁTICOS
}

\author{
Bertha Guzmán Velasco \\ Universidad de Piura
}

Fecha de recepción:

$01 / 08 / 2018$

Fecha de aceptación:

$31 / 10 / 2018$

Saussure estableció en el Curso de lingüística general que todas las unidades (fonológicas, morfológicas, semánticas, etc.) de una lengua están vinculadas entre sí formalmente por medio de dos tipos de relaciones: relaciones asociativas y relaciones sintagmáticas. Las primeras comparten una función lingüística y se distinguen por ser sustituibles en la cadena hablada o escrita —son relaciones verticales o en ausencia-. Por otro lado, la linealidad del signo lingüístico lo lleva a establecer relaciones sintagmáticas, aquí los elementos adquieren un valor comunicativo de acuerdo con los términos que les preceden o suceden. Las relaciones sintagmáticas son de tipo horizontal o en presencia.

https://doi.org/10.46744/bapl.201802.013 
https://doi.org/10.46744/bapl.201802.013

De la interdependencia de estas dos relaciones

se deduce que un 'paradigma' es un conjunto de unidades que pueden conmutar entre sí, es decir, que pueden manifestarse en el mismo contexto y, por tanto, las unidades de un 'paradigma' están en oposición entre sí, o sea, rivalizan por manifestarse en el sintagma. Este se define como el conjunto de unidades del mismo nivel lingüístico en relación de contraste. Los 'paradigmas' y los 'sintagmas' están sometidos a dos operaciones: la elección y la combinación. En el habla o actuación comunicativa, todo hablante elige una unidad de entre las que constituyen el conjunto del paradigma y la combina en el sintagma con la unidad siguiente de otro paradigma (Alcaraz, E. y Martínez, M., 2004: 422-423).

En la relación paradigmática, esta elección del hablante está muy ligada al concepto de «ley del mínimo esfuerzo», rebautizada por algunos autores como «economía lingüística». Es importante explicar a qué se refiere cada una y aclarar que sus denominaciones no son siempre intercambiables.

\section{¿Economía lingüística o ley del mínimo esfuerzo?}

Haremos un breve recorrido por algunos planteamientos de los lingüistas que hablaron de la economía del lenguaje.

Sin temor a ser criticado por relacionar directamente la economía del lenguaje con la pereza del hablante y con la tendencia del hombre a optar por el mínimo esfuerzo, O. Jespersen afirmaba que «el acto de hablar siempre requiere algún esfuerzo, tanto muscular como físico, por parte del hablante, y por lo tanto, en muchas ocasiones es capaz de hablar con el menor esfuerzo posible» (1922: 262).

Sin embargo, ya en 1920, H. Paul señalaba que uno de los errores más comunes consistía en reducir las transformaciones de la lengua a un solo acto como la búsqueda de comodidad: estas modificaciones surgen en un periodo largo de tiempo por una gran cantidad de transformaciones pequeñas. Asimismo, es equivocado ver la causa de un cambio fonético en una especial pereza, dejadez o descuido (57-58). 
https://doi.org/10.46744/bapl.201802.013

Por su parte Zipf, al hablar del mínimo esfuerzo, se aleja de conceptos como la pereza del hablante; al contrario, afirma que lograr que con determinados recursos se logren máximos resultados requiere de un desarrollo cognitivo. Este desarrollo sienta las bases del lenguaje humano.

André Martinet se vale del concepto de «mínimo esfuerzo» planteado por Zipf y lo rebautiza con el nombre de «principio de economía». Para este autor, la «economía» es el resultado de dos fuerzas que están en constante oposición: las necesidades comunicativas y expresivas del hombre y su tendencia a reducir al mínimo su actividad mental y física (1964: 132).

\section{La economía lingüística}

Es necesario replantear la economía de una manera imparcial, lejos de concepciones como la desidia o pereza de los hablantes. El propio Martinet da un paso más respecto a las otras posturas y reconoce que la «economía» recubre todo fundamento lingüístico: reducción de las distinciones inútiles, aparición de nuevas distinciones, mantenimiento del «statu quo» (1964: 132-137).

No podemos negar que el principio de economía tiene un tremendo alcance en todos los niveles de la lengua. Por mencionar algunos casos donde se pone de manifiesto: en la fonología, la segunda articulación nos permite sustentar la construcción de mensajes a partir de un número limitado de fonemas. Asimismo, hay una economía léxica en los sistemas de abreviación (abreviaturas, siglas, acrónimos), así como en los acortamientos léxicos: celu (celular), bici (bicicleta), compu (computadora)... En la morfología, la economía se aprecia en los sustantivos comunes en cuanto al género que marcan la diferencia genérica con la oposición del artículo: el joven/ la joven, el cabo/ la cabo... En el campo de la semántica, los términos homónimos resultan económicos al albergar con un solo significante varios significados. También hay una economía sintáctica en la recategorización de un término; así un adjetivo puede pasar a funcionar como sustantivo gracias al artículo: iQué hombre tonto! frente a Ese hombre es un tonto. 
Vemos que, de alguna u otra manera, la lengua en sus distintos niveles está impregnada por la economía; sin embargo, también es cierto que en estos mismos niveles hay casos que parecen alejarse de este principio. Solo por nombrar algunos: en la morfología, la heteronimia no aprovecha el cambio de morfemas, sino que altera todo el lexema; en la sintaxis, la concordancia entre el sustantivo y el adjetivo; en la semántica, los eufemismos que sustituyen a una palabra con contenido tabú, etc.

Estos casos aparentemente «antieconómicos» encuentran su razón de ser en causas etimológicas, sociales, expresivas, etc., que buscan un mensaje efectivo más allá del ahorro de esfuerzo. Por eso, estamos de acuerdo en que «economía no significa en lingüística una disminución del gasto, sino la organización económica del gasto de energía necesaria para satisfacer las necesidades de la comunicación. Los elementos redundantes, aparentemente «antieconómicos» o innecesarios, son indispensables en la práctica para una comunicación eficaz» (García 2000: 6).

\section{Una «licencia» de la economía lingüística: la homonimia parasitaria}

La tradicional concepción de economía lingüística plantea que en la producción de un mensaje siempre se buscará ahorrar esfuerzo: si hay dos formas de expresar lo mismo, una más complicada que otra, se tiende a optar por la que exige menos esfuerzo. Esto se realizaría muy bien en situaciones perfectas, con hablantes ideales. Sin embargo, la comunicación es un acto real que se lleva a cabo dentro de una situación concreta con las variedades de cada hablante-oyente y las interferencias que puedan aparecer en el contexto.

Por tanto, no siempre el gasto de energía física y mental que se produce en los intercambios lingüísticos tiende a ser proporcional a la cantidad de información transmitida. Algunas de las construcciones que se enmarcan en lo que hoy llamamos «lenguaje políticamente correcto» demandan mayor energía articulatoria; por ejemplo, señor de la tercera edad consta de más unidades que viejo o anciano. Si no se toma en cuenta la primacía que posee la satisfacción de necesidades comunicativas, construcciones como las redundancias, las paráfrasis, algunos eufemismos 
https://doi.org/10.46744/bapl.201802.013

que conllevan la unión de más términos, entre otros recursos, no tendrían cabida en la lengua.

Dentro de estas construcciones altamente expresivas, quiero explicar un singular proceso de formación de palabras: la homonimia parasitaria, que encaja perfectamente en esas «licencias» de la economía lingüística. En su tesis doctoral, el lexicógrafo español y actual investigador de la Real Academia Española, Diego Varela Villafranca, denominó «homonimia parasitaria» al proceso de creación de unidades léxicas en el que un término A cede su significado para unirlo al significante de un término $\mathrm{B}$, preexistente en la lengua, y da origen a un homónimo parasitario, este es un término nuevo constituido con el significado de A y el significante de B. Veamos este ejemplo:

\begin{tabular}{c|c|c}
\multicolumn{1}{c|}{ Término A } & Término B & \multicolumn{1}{c}{ Término C } \\
\hline $\begin{array}{c}\text { Significante: } \\
\text { TALLA }\end{array}$ & $\begin{array}{c}\text { Significante: } \\
\text { TALLARÍN }\end{array}$ & \multicolumn{1}{c}{$\begin{array}{c}\text { Significante B: } \\
\text { TALLARÍN }\end{array}$} \\
\hline $\begin{array}{l}\text { Significado: Estatura } \\
\text { o altura de las } \\
\text { personas. }\end{array}$ & $\begin{array}{l}\text { Significado: Pasta } \\
\text { alimenticia de harina } \\
\text { en forma de tiras } \\
\text { estrechas y largas. }\end{array}$ & $\begin{array}{l}\text { Significado A: } \\
\text { Estatura o altura de las } \\
\text { personas. }\end{array}$ \\
\hline TÉRMINO BASE & $\begin{array}{l}\text { TÉRMINO } \\
\text { MODELO }\end{array}$ & $\begin{array}{c}\text { TÉRMINO } \\
\text { RESULTANTE } \\
\text { Homónimo parasitario }\end{array}$ \\
\hline
\end{tabular}

Ejemplo: Mi tallarín es de $1.70 \mathrm{~cm}$.

Este proceso de formación de palabras siempre presenta un carácter elusivo que puede ser eufemístico (canadá por cárcel; anastasio por ano; cojinova por cojudo) o humorístico (claxon por claro; misión por misio; vegetal por vejete). Nótese que la creación de homónimos parasitarios es plenamente intencionada y obedece a motivaciones fónicas sin relación semántica primaria. 


\section{https://doi.org/10.46744/bapl.201802.013}

En la mayoría de los casos de homonimia parasitaria, el significante conlleva la pronunciación de una mayor cantidad de fonemas - compárese la brevedad del adverbio sí frente al homónimo parasitario cicatriz, con seis fonemas más-; sin embargo, el significado es el mismo. El significado sí mas no el sentido. El término significado alude a una noción lingüística; mientras que el sentido encierra conceptos pragmáticos:

Entendemos por significado de un mensaje el conjunto de informaciones constantes, convencionales e intersubjetivas que se hallan cifradas de acuerdo con las disponibilidades y las reglas que rigen el código de una lengua.

Utilizamos el término sentido para referirnos a la totalidad de contenidos que se transmiten en un mensaje concreto. El sentido depende de un mayor número de factores que el significado (Gutiérrez 2002: 191).

La relación entre significado y sentido está muy ligada en el acto comunicativo, pues una palabra o un conjunto de palabras pueden adquirir distintos sentidos en un contexto. Para explicar esto, recurriremos a cuestiones pragmáticas que permitan aclarar la selección paradigmática del hablante; específicamente, a la teoría de la relevancia planteada por Sperber y Wilson. «Una información no es relevante en sí misma, sino por la relación que mantiene con el contexto, el valor de una misma frase o término puede variar [...]. Un mensaje es tanto más pertinente cuanto mayor sea el número de efectos contextuales o cognitivos que produce» (Gutiérrez 2002: 55).

En el caso de la homonimia parasitaria, es el contexto el que anula el significado original y une el significante con el nuevo significado. Si alguien pronuncia a secas cortina, de seguro en la mente del hablante se unirá este significante al significado 'tela que por lo común cuelga de puertas y ventanas como adorno o para aislar de la luz y de miradas ajenas'. No obstante, en un contexto real de comunicación, por ejemplo, en una conversación, si alguien dice: No voy porque estoy cortina, se descarta inmediatamente el significado anterior. Es precisamente el contexto el que aporta los elementos necesarios para enriquecer las representaciones abstractas y acercarlas a los pensamientos. [...] La representación de un enunciado $-\mathrm{O}$ de un término- no suele quedarse meramente en 
https://doi.org/10.46744/bapl.201802.013

su representación semántica, sino que puede llevar implícitos otros contenidos (Escandell 2006: 112).

Si retomamos la elección paradigmática, valdría ahora ver qué mueve al hablante a realizar todo este proceso de dotar de un nuevo significado a un significante ya existente; por qué crear y elegir los homónimos parasitarios: naranja, mariachi, tarzán cuando ya contamos con nada, marido y tarde, respectivamente. El filósofo Ortega y Gasset estaba convencido de que había que «inventar nuevos modos de la lengua y, originariamente, inventarla en absoluto. Es evidente que se inventan nuevos modos de la lengua, porque los que hay y ella tiene ya no satisfacen, no bastan para decir lo que se tiene que decir» (1964:248).

La comunicación necesariamente está ceñida al contexto y se desarrolla plenamente en él; quien comunica construye por medio de signos convencionales el soporte lingüístico, que sostiene, solo en parte, el decir; debajo subyacen la intencionalidad, las inferencias y, en definitiva, la totalidad del mensaje. Por eso, entender un mensaje es, además de decodificar los signos convencionales de la lengua, entender el propósito del emisor, interpretando tanto lo dicho, como los supuestos y hasta el silencio. En estos principios se basan los conceptos pragmáticos de ostensión/ inferencia: «El estímulo ostensivo atrae la atención del otro y la enfoca en la intención del emisor, tratando de revelar cuál es esa intención» (Escandell 2006: 113).

Como parte de un hecho comunicativo, la creación de un homónimo parasitario debe ser entendida como una construcción intencional cuya modificación en el significante es hecha de manera consciente y ostensiva para atraer la atención del interlocutor. Asimismo, el oyente deberá inferir a qué información alude el hablante, y con qué intención:

Un enunciado es, desde el punto de vista físico, una modificación perceptible del entorno - del entorno sonoro, en el caso de la lengua hablada; del entorno visual, en el caso de la escrita- hecha de manera intencional por un emisor. Desde el momento en que lo reconoce como un estímulo ostensivo de carácter lingüístico, la mente del destinatario 
https://doi.org/10.46744/bapl.201802.013

pone en marcha de manera automática diferentes tipos de procesos: los de decodificación y los de naturaleza inferencial (desde la desambiguación y la asignación de referente hasta la identificación de la intención del emisor) (Escandell 2006: 125).

En el caso de la homonimia parasitaria parece ser que se combinan los procesos de codificación y ostención porque es este nuevo término codificado el que funciona a su vez como estímulo ostensivo. Así, el estímulo verbal — significante — se despoja de su significado original para señalar otra realidad — la de un nuevo significado—, y es el receptor quien finalmente, a través de un proceso inferencial, reconstruye el mensaje y recupera la intención — humorística o eufemística — que hay tras el enunciado.

Aunque la intencionalidad está presente en la creación de cualquier mensaje, comporta una especial importancia en la hominimia parasitaria. Tanto desde la postura del hablante como de la del oyente, pues es este último quien debe captar que el homónimo parasitario es un estímulo ostensivo que encierra la intención de alterar el significado de un significante. Este es el punto de partida para luego reconstruir el verdadero sentido gracias al contexto.

\section{La economía lingüística y la homonimia parasitaria}

Para analizar la homonimia parasitaria a la luz de la economía lingüística tenemos que separar el análisis en los roles del hablante y del oyente, es decir, hablaremos de la economía en la producción y en la interpretación del mensaje.

Desde el punto de vista de la producción, y según lo planteado por Martinet, parece ser que la creación de un homónimo parasitario supone una economía paradigmática, ya que, como en todo caso de homonimia, se utilizan significantes presentes en la lengua. En este caso surge un neologismo que aprovecha un significante y lo revitaliza dotándolo de un nuevo significado - a su vez, este ha sido tomado de otra unidad lingüística-; este procedimiento configura un ahorro léxico pues se 
aprovecha una pieza ya existente en la lengua. Sin embargo, desde una perspectiva sintagmática, esta creación requiere un mayor gasto porque, en la mayoría de los casos, la extensión formal del término modelo demanda más energía articulatoria y, por ende, acústica.

El papel que juega el homónimo parasitario en la economía se mide por los efectos contextuales. Por un lado, el hablante espera que los resultados sean tan importantes que compensen la energía de procesar el enunciado; del otro, se presume que el esfuerzo que tendrá que invertir el oyente no será mayor de lo necesario para conseguir los alcances contextuales pretendidos. De acuerdo con el segundo principio de relevancia,

comunicarse implica que la información que uno va a dar es relevante, o sea, que vale la pena el esfuerzo de atención que se requiere del oyente. El principio de relevancia explica la interacción entre el significado de las palabras y los datos del contexto: el hecho de que un enunciado significa algo en un determinado contexto no se explica, como en la teoría de Grice, por principios de comportamiento, sino por principios cognoscitivos generales (Reyes 2007: 57).

Por eso, aunque se vea transgredida la economía sintagmática al usar términos que demandan mayor coste articulatorio en la emisión, el homónimo parasitario es un estímulo ostensivo y, como tal, «crea expectativas precisas de que su procesamiento supondrá un equilibrio entre el esfuerzo invertido y los efectos obtenidos; y son estas expectativas precisas las que guían al destinatario en la interpretación» (Escandell, 2006: 124). En definitiva, el hablante considera que los efectos de sentido producidos merecen el esfuerzo cognitivo del oyente para su interpretación. Un homónimo parasitario no puede ser reemplazado por el término original — término base- y continuar surtiendo las mismas consecuencias cognitivas en la mente del receptor; en su uso existe una fuerte carga de sentido que escapa a la mera decodificación.

En definitiva, ¿qué motiva al hablante a optar por un término de mayor coste en la pronunciación? En esta elección paradigmática, el emisor selecciona, de entre todos los enunciados posibles, aquel 
que para su interlocutor pueda dar lugar a mejores efectos con un coste de procesamiento razonablemente bajo. Esto supone que el que comunica utiliza el estímulo que le parece más relevante - en este caso el homónimo parasitario- para la persona cuyo entorno trata de modificar. Este principio pragmático de relevancia es una generalización en el funcionamiento de la comunicación y, como tal, engloba al caso de la homonimia parasitaria.

Desde un punto de vista de la interpretación, la desambiguación del significado de un homónimo parasitario gracias a la previsibilidad contextual también constituye otro factor de economía. Cuando se enuncia una expresión como Este es bien cojinova, se entiende que el hablante no se está refiriendo al nombre de ningún pez, sino que está calificando a alguien con el adjetivo de cojudo. ¿Cómo se llegó a tal conclusión? A través de un proceso inferencial: el oyente busca dentro de sus conocimientos previos; además, gracias al contexto, sabe que elegir el significado de 'pez marino de carne comestible, que habita desde la costa norte del Perú hasta la costa norte de Chile' resultaría inadecuado; entonces, se inclina por encontrar un significado idóneo a la situación, aquel que le permita una interpretación pertinente. Gracias a la semejanza de los tres primeros fonemas de los dos términos, el receptor puede inferir que hay un proceso de reemplazo en los significantes con la conservación del significado: el homónimo parasitario cojinova se ha usado para no pronunciar directamente la palabra cojudo. Como señala Gutiérrez Ordoñez:

Esta encrucijada significativa rara vez produce perplejidad en el que interpreta un mensaje. El usuario de la lengua se inclina de forma casi automática hacia uno de los sentidos posibles. ¿Hacia cuál? Hacia aquella interpretación que sea más relevante, es decir, que menor coste de procesamiento exija y que mayor número de efectos contextuales genere (2002: 153).

\section{Conclusión}

Para terminar con esta exposicion señalaremos que en la elección paradigmática se ponen en juego diversos factores: lingüísticos, sociales, 
https://doi.org/10.46744/bapl.201802.013

expresivos, etc. Media entre ellos el principio de economía, que no se sustenta en la pereza ni en la inercia del hablante, sino en complejos procesos cognitivos que se orientan a organizar y disponer de los recursos para obtener la máxima productividad. Sin embargo, junto al concepto de economía lingüística se encuentra la satisfacción de las necesidades comunicativas, esta con toda la riqueza que conlleva precede a cualquier otro principio y es el fundamento de la construcción del mensaje. 
https://doi.org/10.46744/bapl.201802.013

\section{BIBLIOGRAFÍA}

ALCARAZ VARÓ, E. y MARTÍNEZ LINARES, M. (2004). Diccionario de lingüistica moderna, Barcelona, Ariel.

ESCANDELL, M. V. (2006). Introducción a la pragmática. Barcelona, Ariel.

GARCÍA AGUSTÍN, O. (2000). «La teoría del decir: La nueva lingüística según Ortega y Gasset» en Cuadernos de investigación filológica, volumen xxvi.

GUTIÉRREZ ORDÓÑEZ, S. (2002). De pragmática y semántica. Madrid, Arco/Libros.

JESPERSEN, O. (1922). Language; its nature, development and origin. Londres, George Allen \& Unwin Ltd..

MARTINET, A. (1964). Économie des changements phonétiques. Traité de phonologie diachronique, Berna, A. Francke [vers. esp.: Madrid, Gredos, 1974].

ORTEGA Y GASSET, J. (1964). «Obras completas» en Revista de Occidente, Madrid, volumen vii.

PAUL, H. (1975). Prinzipien der Sprachgeschichte. Tubinga, Max Niemeyer, 1920.

REYES, G. (2007). El abc de la pragmática. Madrid, Arco/Libros.

VARELA VILLAFRANCA, D. (2016). Un sistema peculiar de creación de palabras en español: descripción y análisis de la homonimia parasitaria (tesis doctoral), Madrid, Universidad Autónoma de Madrid. 